\title{
Comparative studies of the Ainu, their ancestors, and neighbors: assessment based on metric and nonmetric dental data
}

\author{
Masanori KABURAGi $^{1,3}$, Hajime IshIDA ${ }^{2}$, Masaaki Goto ${ }^{3}$, Tsunehiko HANIHARA ${ }^{4 *}$ \\ ${ }^{1}$ Department of Anatomy and Biological Anthropology, Saga Medical School, Saga 849-8501, Japan \\ ${ }^{2}$ Department of Anatomy, Faculty of Medicine, University of the Ryukyus, Nishihara 903-0215, Japan \\ ${ }^{3}$ Department of Oral and Maxillofacial Surgery, Saga Medical School, Saga 849-8501, Japan \\ ${ }^{4}$ Department of Anatomy, Kitasato University School of Medicine, Sagamihara 252-0374, Japan
}

Received 3 June 2009; accepted 16 September 2009

\begin{abstract}
Using Mahalanobis' generalized distance for odontometric data and Smith's mean measure of divergence for nonmetric dental data, interpopulation similarities between four local Ainu groups from Sakhalin Island and Hokkaido, as well as their supposedly ancestral and neighboring populations, were analyzed. In this study, multidimensional scaling and multidimensional plots by Andrews were applied to the distance matrices to visualize the intergroup relationships. The results obtained reconfirm the dental association between the prehistoric Jomon and the recent Ainu. However, the diversity of the recent Ainu in Hokkaido is not necessarily accommodated in a single regional populational lineage, the Jomon. The present findings also suggest that admixture between the immigrants from Northeast Asia as represented by the Okhotsk culture people and the indigenous inhabitants in Hokkaido during the 5th-12th centuries $\mathrm{AD}$ may in part have contributed to the formation of the physical characteristic of the recent Ainu. In particular, the female Okhotsk culture sample shows closer affinity to the northeastern Hokkaido and the Sakhalin Ainu in some of the analyses presented in this study. Such findings are compatible with those obtained by craniometric analyses, supporting the hypothesis of higher migration rates among females than among males due to patrilocality or the shorter matrilineal generation interval.
\end{abstract}

Key words: Okhotsk culture people, Northeast Asia, admixture, Jomon, population history

\section{Introduction}

It is generally accepted that Japan has two related but ethnically and physically distinguishable major population groups, the Ainu, the indigenous inhabitants of Hokkaido, and the non-Ainu Japanese. This consensus emerged in the 1960s (Yamaguchi, 1967, 1973; Hanihara, 1968, 1970; Omoto, 1972), and was re-evaluated in the 'dual structure model' of the origins and affinities of Japanese proposed by Hanihara (1991).

Patterns of genetic variation and morphological traces can be interpreted as showing that the Ainu and non-Ainu Japanese have deep roots in the Neolithic Jomon population (Yamaguchi, 1982; Turner, 1987, 1990; Brace and Hunt, 1990; Dodo and Ishida, 1990; Kozintsev, 1990, 1992; Horai et al., 1991; Omoto and Saitou, 1997; Ossenberg et al., 2006). The incoming populations bringing rice agriculture and metalworking technologies from the continental East/ Northeast Asia to southwestern part of Japan, the main ancestors of current non-Ainu Japanese, began to disperse

* Correspondence to: Tsunehiko Hanihara, Department of Anatomy, Kitasato University School of Medicine, 1-15-1 Kitasato, Minamiku, Sagamihara 252-0374, Japan.

E-mail: hanihara@med.kitasato-u.ac.jp

Published online 1 December 2009

in J-STAGE (www.jstage.jst.go.jp) DOI: 10.1537/ase090603 across the entire Japanese archipelago in the period from the end of the Jomon age to the early historic age, from 2300 years BP to 1300 years BP (Yamaguchi, 1982; Turner, 1987; Hanihara, 1991; Habu, 2004). However, such waves of expansion and the subsequent admixture between the immigrants and the indigenous people did not reach geographically isolated Hokkaido (Turner, 1987; Hanihara, 1991; Fitzhugh and Dubreuil, 1999). The historic time periods of Hokkaido after the Jomon period are, therefore, different from those of main-island Japan and divided as follows: EpiJomon (2300-1300 years BP), Satsumon (1300-700 years $\mathrm{BP})$, and Ainu culture periods.

During the 5 th-12th centuries AD, migration of people with a distinct culture, known as the Okhotsk culture, from Northeast Asia into Hokkaido has been identified (Amano, 2003). This culture, characterized by considerable maritime structure, spread along the coastal region of the Sea of Okhotsk to the easternmost part of Hokkaido (Ishida, 1988; Amano, 2003; Sato et al., 2007). In spite of such migration and a possible gene flow from this external source, the present Ainu retain a good number of genetic and phenotypic characteristics shared by the prehistoric Hokkaido inhabitants represented by the Jomon (Howells, 1986; Turner, 1987, 1990; Hanihara, 1991; Horai et al., 1991; Dodo and Ishida, 1990; Brace et al., 2001; Dodo and Kawakubo, 2002; Ossenberg et al., 2006).

Many dental anthropologists see the Ainu (and the 
Jomon) as Southeast Asian sundadonts (Turner, 1987, 1990, 1992a, b; Hanihara, 1991; Matsumura, 1995, 2007; Matsumura and Hudson, 2005; Manabe et al., 2008; Matsumura et al., 2009). It is often pointed out, moreover, that extensive dental size reduction occurs exclusively in Ainu and their Jomon predecessors, together with the Philippine Negritos in eastern Asia (Brace et al., 1989, 1991; Brace and Hunt, 1990; Hanihara and Ishida, 2005; Matsumura and Hudson, 2005).

Contrary to several lines of dental anthropological evidence, many genetic investigations suggest that the Ainu (and Jomon) are members of populations originating in Northeastern Asian (Nei, 1995; Omoto, 1995; Omoto and Saitou, 1997; Tajima et al., 2004; Adachi et al., 2009). This perceived affinity of the Ainu with Northeast Asians at the genetic level has often been contrasted with what are seen as substantial and obvious differences at the craniofacial morphological level (Yamaguchi, 1982; Hanihara, 1991; Dodo and Ishida, 1990; Ossenberg et al., 2006).

Although many investigations have shown that the Ainu and Jomon differ in their morphological characteristics from the neighboring population groups, recent studies based on nonmetric cranial traits and quantitative genetic analyses developed by Relethford and Blangero (1990) and Relethford (1994) suggest a possible genetic influence from Northeast Asians on the formation of physical characteristic of the recent Ainu (Shigematsu et al., 2004; Komesu et al., 2008; Hanihara et al., 2008; Hanihara and Ishida, 2009; Hanihara, $2010 \mathrm{a}, \mathrm{b})$. However, similar assessments have not been elucidated from a classic dental anthropological approach (Manabe et al., 2008; Matsumura et al., 2009).

Given this background, we test for the presence of northern elements brought mainly by the Okhotsk culture people in dental features of the Ainu by analyzing the affinities between four local Ainu groups and four comparative series covering temporal and spatial scales in order to understand the possible process of population differentiation.

\section{Materials and Methods}

The materials of the Ainu are derived from four geographic regions: Sakhalin Island, southwestern Hokkaido, southeastern Hokkaido, and northeastern Hokkaido. Groupings of the three Hokkaido series are based on the administrative divisions of subprefectures, which correspond almost exactly to watersheds (Kondo, 1995; Hanihara et al., 2008; Hanihara, 2010a, b). The four comparative samples were selected in order to estimate patterns of morphological resemblance and dissimilarities between Ainu and their spatial and temporal neighbors: the Neolithic Jomon from Hokkaido and Tohoku region, Epi-Jomon/Satsumon, Okhotsk culture people, and modern non-Ainu Japanese.

Brief information on the nature of the eight samples is given in Table 1. Figure 1 presents the location of the population groups investigated. The northeastern region of Hokkaido overlaps the area containing the sites of the Okhotsk culture people that have been discovered thus far (Shigematsu et al., 2004; Hanihara et al., 2008; Hanihara, 2010a, b).

In the present study, morphological variation and differentiation was evaluated using metric and nonmetric dental data. The metric data consist of mesiodistal and buccolingual crown diameters of all right teeth, a total of 32 variables. When a right tooth was missing or badly damaged, the corresponding left tooth was measured. Nonmetric trait observations were made on 11 crown variables in the permanent dentition. Table 2 shows the criteria used to score the nonmetric crown traits (Hanihara, 2008, 2010a). All the data were recorded by one of the present authors (T.H.) to avoid possible interobserver errors. The nonmetric traits used in

Table 1. Material used and brief information

\begin{tabular}{|c|c|}
\hline Sample name & Brief information \\
\hline \multicolumn{2}{|l|}{ Recent Ainu } \\
\hline \multicolumn{2}{|l|}{ Hokkaido } \\
\hline \multirow[t]{2}{*}{ Southwest } & Sapporo and the neighboring cities (Ishikari subprefecture) (University of Tokyo, Sapporo Medical University) \\
\hline & Otaru, Yoichi, and Iwanai (Shiribeshi subprefecture) (University of Tokyo) \\
\hline \multirow[t]{2}{*}{ Southeast } & Hiroo and Ohtsu (Tokachi subprefecture) (University of Tokyo) \\
\hline & $\begin{array}{l}\text { Urakawa, Atsubetsu, Horoizumi, Mitsuishi, Saru, Shizunai, and Urakawa (Hidaka subprefecture) (University of } \\
\text { Tokyo, Sapporo Medical University) }\end{array}$ \\
\hline \multirow{2}{*}{ Northeast } & Abashiri, Monbetsu, Shari, and Tokoro (Abashiri subprefecture) (University of Tokyo, Sapporo Medical University) \\
\hline & Nemuro (Nemuro subprefecture) (University of Tokyo, Sapporo Medical University) \\
\hline Sakhalin Island & Sakaehama and Honto villages (Kyoto University) \\
\hline \multicolumn{2}{|l|}{ Comparative samples } \\
\hline \multirow[t]{2}{*}{ Jomon/Hokkaido and Tohoku } & $\begin{array}{l}\text { Usu-Moshiri, Kitakogane, Takasago, Irie, Motowa-Nishi (Iburi), Yakumo-Kotan (Oshima), Tenneru (Kushiro), } \\
\text { Shimamaki (Shiribeshi), and other sites in Hokkaido }\end{array}$ \\
\hline & Ebishima, Nakazawahama, Ohora, Hosoura (Iwate Prefecture), Sanganji (Fukushima Prefecture), Sakai-Numazu, \\
\hline \multirow[t]{2}{*}{ Epi-Jomon/Satsumon } & Epi-Jomon samples: Ohkawa, Ikeda 3 (Shiribeshi), and Usu sites (Iburi) \\
\hline & Satsumon samples: Oyakotsu (Iburi) and Ohkawa sites (Shiribeshi) \\
\hline Okhotsk culture people & $\begin{array}{l}\text { 5-12 century AD Hamanaka (Rebun Island), Ohmisaki (Soya), Moyoro (Abashiri), and Susuya sites (Sakhalin } \\
\text { Island) (Hokkaido University, Sapporo Medical University, Kyoto University) }\end{array}$ \\
\hline Modern Japanese & Mainly from Tokyo (University of Tokyo) \\
\hline
\end{tabular}




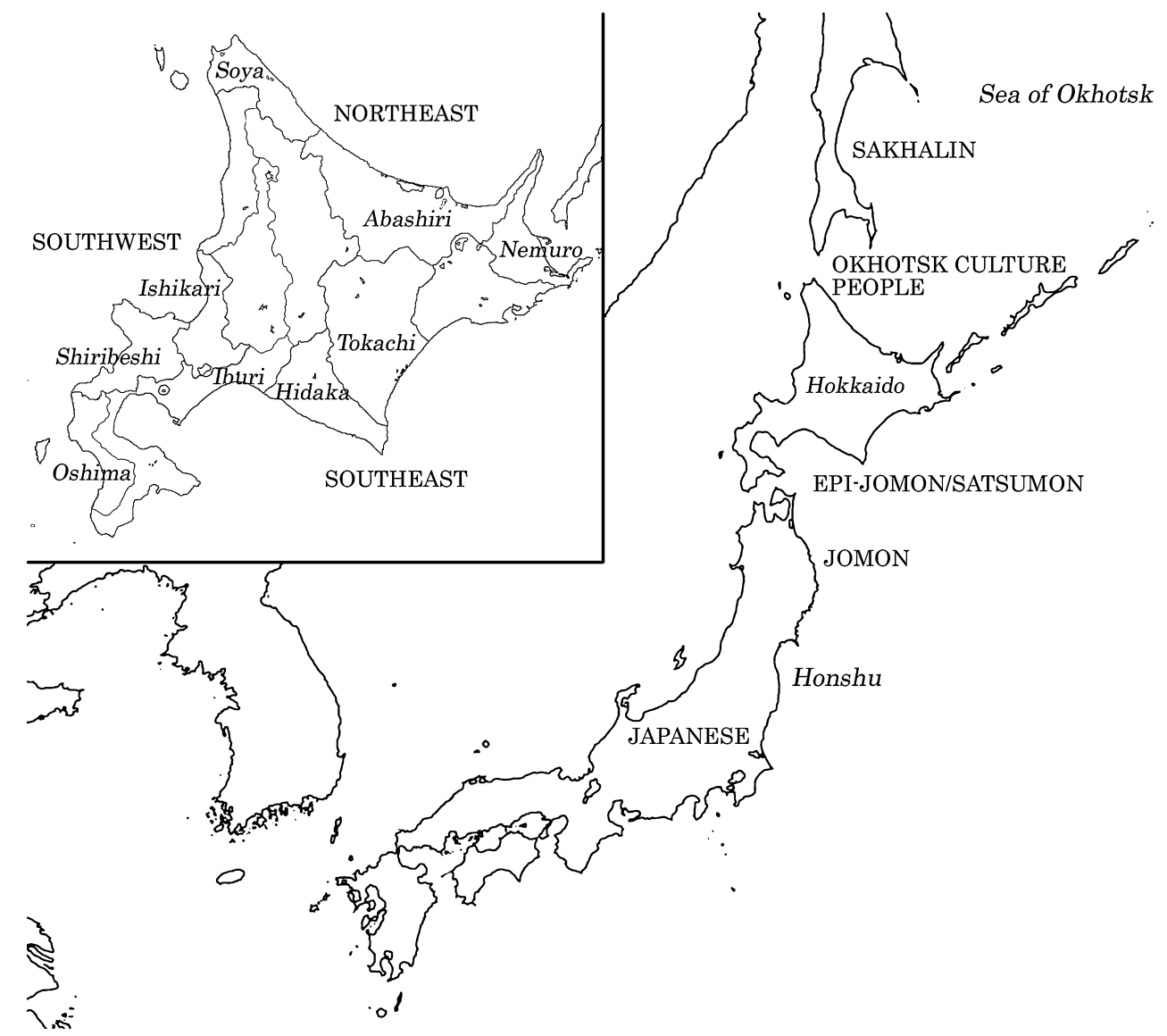

Figure 1. Geographical location of the dental samples used (capital letters) in the present study.

Table 2. Standards for the 11 nonmetric dental traits

\begin{tabular}{|c|c|}
\hline Trait observed & Criteria \\
\hline 1. Shoveling (UI1) & The depth of Lingual fossa deeper than $0.5 \mathrm{~mm}$ is scored as present (Hanihara et al., 1970). \\
\hline 2. Shoveling (UI2) & $\begin{array}{l}\text { The teeth classified as the ASU system's grade 3-7 are scored as present (Turner et al., 1991; Scott and Turner, } \\
\text { 1997). }\end{array}$ \\
\hline 3. Carabelli's cusp (UM1) & Dahlberg's (1963) d-g grade is scored as present. \\
\hline 4. Hypocone (UM2) & Presence corresponds to 4- and 4+ of Plaque P9, Dahlberg (1949). \\
\hline 5. Sixth cusp (LM1) & Cusp is scored as present regardless of the size (ASU system). \\
\hline 6. Seventh cusp (LM1) & Cusp is scored as present regardless of the size (ASU system). \\
\hline 7. Deflecting wrinkle (LM1) & $\begin{array}{l}\text { Following Weidenreich (1937), if the medial ridge of metaconid deflected distally, the trait is scored as present. } \\
\text { Presence corresponds to grade } 2-3 \text { of the ASU system. }\end{array}$ \\
\hline 8. Protostylid (LM1) & The ASU system's $2-7$ were scored as present. \\
\hline 9. Distal trigonid crest (LM1) & Follows the original description by Weidenreich (1937). \\
\hline 10. Hypoconulid (LM2) & Follows the ASU system. \\
\hline 11. Sixth cusp (LM2) & Follows the ASU system. \\
\hline
\end{tabular}

this study include crown characters defined as Mongoloid dental complex (Hanihara, 1968), four out of six key crown traits distinguishing sundadonty from sinodonty (Turner, 1990), Caucasoid dental complex (Mayhall et al., 1982), Australian proto-sundadont dental pattern (Hanihara, 1992), and sub-Saharan African dental complex (Irish, 1997, 1998). For nonmetric dental data, sexes were combined since the difference in frequency distributions by sex was not significant in most of the samples (Hanihara, 2008, 2010b). While nonmetric observations were made on both the right and left antimeres for each trait, the individual count method was used: if a trait was present on either or both sides, it was scored as present (Turner et al., 1991; Hanihara et al., 2003; Hanihara, 2008).

The analytical approaches applied in this study are classic multivariate procedures such as Mahalanobis' generalized distance and Smith's mean measure of divergence (MMD) distance (Mahalanobis, 1936; Berry and Berry, 1967; Constandse-Westermann, 1972). For metric data, the raw measurements were converted into $C$-scores according to the procedure described by Howells (1989) and Brace and Hunt (1990). Although some researchers have criticized the 
application of $C$-score data to multivariate analyses (e.g. Jungers et al., 1995), the transformation to $C$-scores has little effect on the reliability of the pattern of interpopulation relationships (Pietrusewsky, 1997; Kawakubo et al., 2009). After transforming raw data to $C$-scores by the double centering method, the effects of dental size factors can be removed from the data. In the present study, the validity of the normal distribution of the $C$-scores for each variable was examined in the Japanese sample (with relatively large sample size) using P-P and Q-Q plots.

To visualize the patterning of intergroup relationships, the multidimensional scaling (MDS) method developed by Torgerson (1952) was applied to the distance matrices obtained. In addition to the two (or three) dimensional display, the multidimensional plot by Andrews (1972) was used to illustrate information obtained by MDS. In this method, multidimensional scores for each sample with $p$ variables $\left(x_{1}, x_{2}\right.$, $\left.\ldots, x_{p}\right)$ are entered in a Fourier trigonometric function:

$$
f t\left(x_{1}, x_{2}, \ldots, x_{p}\right)=x_{1} \sqrt{2}+x_{2} \sin t+x_{3} \cos t+x_{4} \sin 2 t
$$$$
+x_{5} \cos 2 t+\ldots+x_{p} \sin (p t / 2)
$$

where $\mathrm{p}$ is an even number, and

$$
\begin{aligned}
f t\left(x_{1}, x_{2}, \ldots, x_{p}\right)= & x_{1} \sqrt{2}+x_{2} \sin t+x_{3} \cos t+x_{4} \sin 2 t \\
& +x_{5} \cos 2 t+\ldots+x_{p} \cos ((p-1) t / 2),
\end{aligned}
$$

where $p$ is an odd number. The values of $t$ (and thus of $f$ ) are periodic over the range of $-\pi$ to $+\pi$. The value of $f$ is plotted for values of $t$ along this scale to form the curve for each group.

\section{Results}

Table 3 gives the results of basic statistics of dental measurements for male and female samples separately. Descriptive statistics for nonmetric traits are presented in Table 4.

In the metric data analyses, $C$-score-based Mahalanobis' generalized distances between every pair of samples were calculated for sex-combined samples (Table 5). Before the male and female samples were pooled, the $Z$-score standardization was performed within each sex separately (Relethford, 1994, 2009; Hanihara et al., 2008). Prior to applying multivariate analyses, possible sampling errors due to the small sample size of the upper and lower first incisors of the northeastern Hokkaido Ainu sample (less than 10 individuals in the sex-combined case) was examined. The correlation between Mahalanobis generalized distance matrices based on 32 measurements and 28 measurements (excluding mesiodistal and boccolingual crown diameters of the upper and lower first incisors) evaluated by mantel test was 0.984 $(P<0.001)$. Such findings may allow us to use all the items measured for multivariate analyses.

In the present study, though preliminary, Mahalanobis' generalized distances for each sex were calculated (Table 6) to investigate sex-related difference of intergroup relationships observed in craniometric analyses (Hanihara et al., 2008).

Multidimensional scaling was applied to the distance matrices. Table 7 gives the information obtained from this dimension-reduced procedure. Figure 2 is a plot of the groups on the first two dimensions for sex-pooled samples as well as separately for the male and female samples. Relative to the Ainu populations, the most peripherally posi- tioned group is modern Japanese, followed by the Jomon and Epi-Jomon/Satsumon series. The Jomon and the subsequent Epi-Jomon/Satsumon samples show closer affinities to either or both the southwestern and southeastern Hokkaido Ainu series than to the northeastern Hokkaido and Sakhalin Ainu series, although this pattern is not clear in females. The three Ainu samples from Hokkaido tend to form a cluster. Among four recent Ainu series, the Sakhalin Ainu sample show a relatively dispersed arrangement in both scattergrams and the distance values themselves. The Okhotsk culture series shows inconsistent arrangement in the three scattergrams (Figure 2a, b, c). The Okhotsk culture sample is plotted between the Sakhalin Ainu and Hokkaido Ainu samples in the sex-pooled analysis. In the male samples, the Okhotsk series shares similar dental features with those of the Japanese sample on the first axis, which expresses approximately $60 \%$ of the total variance. They show close affinities to northeastern Hokkaido Ainu on the second axis, expressing approximately $17 \%$ of the total variance. On the other hand, the Okhotsk sample falls within the Hokkaido Ainu cluster in the female case. The biological distances between the Okhotsk culture series and recent Ainu samples shown in Table 5 and Table 6 suggest the inheritance of northern element in the odontometric characteristics of the Sakhalin and northeastern Hokkaido Ainu series.

Next, multivariate procedures are applied to the nonmetric dataset recorded in the same samples used in the metric analyses. The information for the results of MDS applied to the Smith's MMD given in Table 8 is presented in Table 9. Figure 3 shows the two-dimensional expression of the intergroup relationship that results from MDS. The modern Japanese and Epi-Jomon/Satsumon dental series form differentiated constellations. The dental series of the Ainu are scattered within a grouping that includes the Jomon. The Okhotsk culture series are slightly removed from this clustering. The northeastern Hokkaido Ainu sample, when seen on the first axis representing approximately $70 \%$ of the total variance, shows close affinity to the Okhotsk culture sample. The close affinity between the northeastern Hokkaido Ainu and the Okhotsk culture series is also suggested in the MMD distance matrix shown in Table 8 .

Figure 4 and Figure 5 are drawn using the multidimensional plots of Andrews (1972) to display information obtained by MDS based on Mahalanobis' generalized distance and Smith's MMD distance, respectively. In these figures, the dimensions extracted by MDS modulate a plotted curve for each group, which allows a visual impression of the degree of conformity among them. This method can remove certain limitations of clustering or of having to plot the relative positions of groups on only two or three axes at a time (Howells, 1986; Hanihara, 1997). In this analysis, we focus on possible affinities between the four Ainu dental series and the Okhotsk culture series which are suggested in the previous presentations (Figure 2, Figure 3). In Figure 4, the curve of the Sakhalin Ainu and to a lesser extent the northeastern Hokkaido Ainu series show a different pattern from that of the southwestern and southeastern Hokkaido Ainu samples. In the female samples, the curve of the northeastern Hokkaido Ainu sample deviates in the direction of 


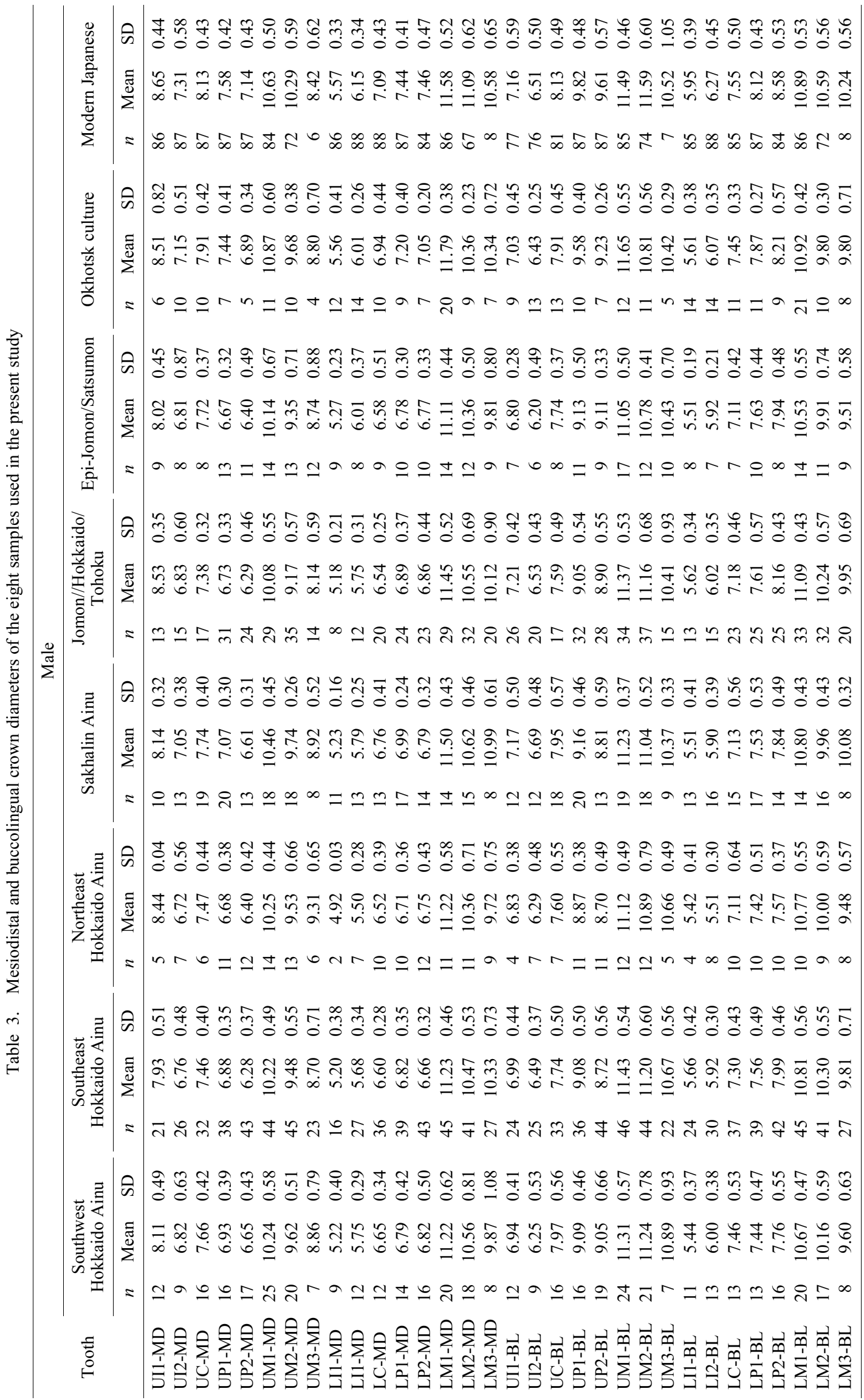




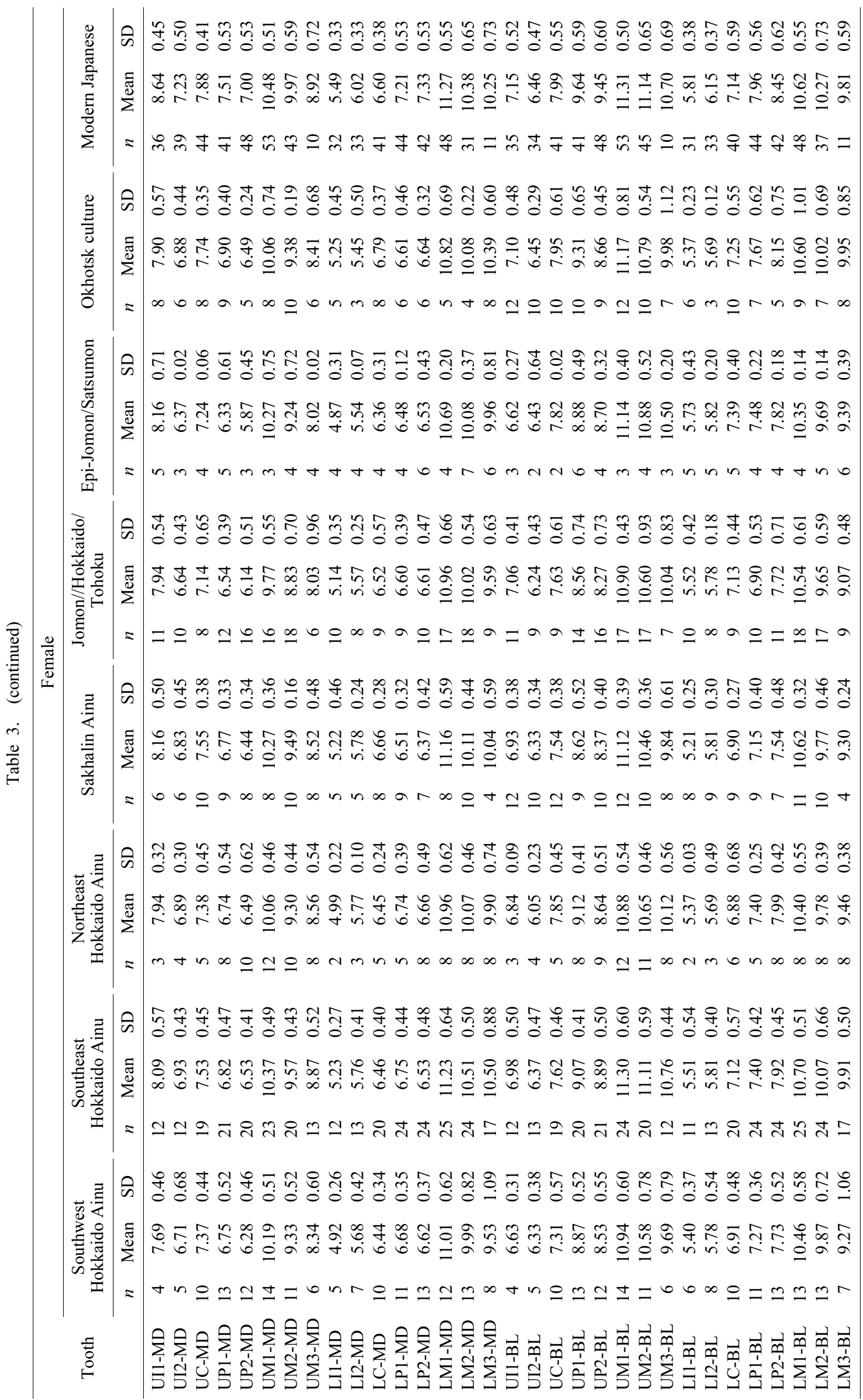


Table 4. Frequencies of nonmetric crown traits for eight samples

\begin{tabular}{|c|c|c|c|c|c|c|c|c|}
\hline \multirow{2}{*}{ Traits (tooth) } & \multicolumn{2}{|c|}{ Southwest Ainu } & \multicolumn{2}{|c|}{ Southeast Ainu } & \multicolumn{2}{|c|}{ Northeast Ainu } & \multicolumn{2}{|c|}{ Sakhalin Ainu } \\
\hline & $n$ & Freq. & $n$ & Freq. & $n$ & Freq. & $n$ & Freq. \\
\hline Shovel (UI1) & 14 & 0.7143 & 29 & 0.7586 & 5 & 0.6000 & 25 & 0.8000 \\
\hline Shovel (UI2) & 14 & 0.8571 & 32 & 0.7500 & 13 & 0.7692 & 25 & 0.9200 \\
\hline Carabelli's cusp (UM1) & 36 & 0.0556 & 63 & 0.0317 & 19 & 0.0000 & 28 & 0.1071 \\
\hline Hypocone (UM2) & 35 & 0.8286 & 65 & 0.7538 & 22 & 0.6818 & 33 & 0.8485 \\
\hline 6th cusp (LM1) & 30 & 0.2333 & 66 & 0.1970 & 13 & 0.0769 & 27 & 0.1111 \\
\hline 7th cusp (LM1) & 32 & 0.0625 & 66 & 0.0455 & 15 & 0.0000 & 30 & 0.0667 \\
\hline Deflecting wrinkle (LM1) & 22 & 0.1818 & 48 & 0.1875 & 7 & 0.5714 & 23 & 0.3043 \\
\hline Distal trigonid crest (LM1) & 27 & 0.2222 & 59 & 0.1525 & 10 & 0.3000 & 24 & 0.1250 \\
\hline Protostylid (LM1) & 27 & 0.0000 & 59 & 0.0508 & 15 & 0.0667 & 21 & 0.0476 \\
\hline Hypoconulid (LM2) & 32 & 0.4062 & 59 & 0.5085 & 17 & 0.5882 & 30 & 0.6000 \\
\hline 6th cusp (LM2) & 29 & 0.1379 & 58 & 0.0862 & 16 & 0.0625 & 29 & 0.1379 \\
\hline \multirow{2}{*}{ Traits (tooth) } & \multicolumn{2}{|c|}{ Jomon } & \multicolumn{2}{|c|}{ Epi-Jomon/Satsumon } & \multicolumn{2}{|c|}{ Okhotsk Culture } & \multicolumn{2}{|c|}{ Modern Japanese } \\
\hline & $n$ & Freq. & $n$ & Freq. & $n$ & Freq. & $n$ & Freq. \\
\hline Shovel (UI1) & 21 & 0.6667 & 7 & 0.7143 & 14 & 0.8571 & 69 & 0.9855 \\
\hline Shovel (UI2) & 28 & 0.8214 & 6 & 0.6667 & 17 & 0.9412 & 69 & 0.8696 \\
\hline Carabelli's cusp (UM1) & 29 & 0.1379 & 14 & 0.0000 & 14 & 0.0000 & 70 & 0.1000 \\
\hline Hypocone (UM2) & 44 & 0.7500 & 15 & 0.9333 & 12 & 0.9167 & 64 & 0.9375 \\
\hline 6th cusp (LM1) & 38 & 0.3684 & 14 & 0.2857 & 26 & 0.1923 & 59 & 0.4237 \\
\hline 7th cusp (LM1) & 44 & 0.0682 & 13 & 0.0000 & 25 & 0.0400 & 51 & 0.0588 \\
\hline Deflecting wrinkle (LM1) & 29 & 0.2759 & 10 & 0.0000 & 21 & 0.6190 & 30 & 0.2000 \\
\hline Distal trigonid crest (LM1) & 32 & 0.0313 & 12 & 0.0000 & 24 & 0.2917 & 28 & 0.0000 \\
\hline Protostylid (LM1) & 29 & 0.1034 & 12 & 0.0000 & 25 & 0.0400 & 59 & 0.0339 \\
\hline Hypoconulid (LM2) & 47 & 0.6170 & 17 & 0.5294 & 13 & 0.6154 & 50 & 0.7200 \\
\hline 6th cusp (LM2) & 39 & 0.1538 & 16 & 0.1250 & 13 & 0.0000 & 43 & 0.0930 \\
\hline
\end{tabular}

Table 5. Mahalanobis' generalized distance based on C-scores for sex-combined sample

\begin{tabular}{|c|c|c|c|c|c|c|c|c|}
\hline & 1 & 2 & 3 & 4 & 5 & 6 & 7 & 8 \\
\hline 1. Southwest Hokkaido Ainu & - & & & & & & & \\
\hline 2. Southeast Hokkaido Ainu & 35.2643 & - & & & & & & \\
\hline 3. Northeast Hokkaido Ainu & 27.7479 & 43.5357 & - & & & & & \\
\hline 4. Sakhalin Ainu & 37.2484 & 48.7207 & 45.1142 & - & & & & \\
\hline 5. Jomon & 62.9433 & 31.6490 & 71.9023 & 80.9072 & - & & & \\
\hline 6. Epi-Jomon/Satsumon & 34.4193 & 48.8817 & 42.8842 & 72.5704 & 64.1336 & - & & \\
\hline 7. Okhotsk culture & 57.8424 & 76.2251 & 69.1894 & 51.5562 & 95.8866 & 55.3584 & - & \\
\hline 8. Japanese & 81.0241 & 97.7207 & 84.6173 & 104.9581 & 121.7003 & 76.4812 & 71.5183 & - \\
\hline
\end{tabular}

Table 6. Mahalanobis' generalized distance based on C-scores for male (upper half) and female (lower half) samples

\begin{tabular}{|c|c|c|c|c|c|c|c|c|}
\hline & 1 & 2 & 3 & 4 & 5 & 6 & 7 & 8 \\
\hline 1. Southwest Hokkaido Ainu & - & 38.4727 & 38.7443 & 43.3752 & 59.8205 & 42.7582 & 77.3502 & 80.7673 \\
\hline 2. Southeast Hokkaido Ainu & 39.6322 & - & 43.2083 & 45.6003 & 23.5454 & 59.0356 & 91.4448 & 90.9620 \\
\hline 3. Northeast Hokkaido Ainu & 32.0409 & 36.0576 & - & 51.0443 & 62.7989 & 50.4958 & 76.4458 & 89.1416 \\
\hline 4. Sakhalin Ainu & 39.4992 & 43.2099 & 63.9988 & - & 73.8479 & 63.4164 & 66.2583 & 80.0959 \\
\hline 5. Jomon & 70.0876 & 33.0832 & 64.8219 & 66.8513 & - & 73.8654 & 106.4459 & 106.6863 \\
\hline 6. Epi-Jomon/Satsumon & 86.9337 & 77.6011 & 83.3138 & 109.3591 & 70.0906 & - & 44.7720 & 53.1390 \\
\hline 7. Okhotsk culture & 54.0404 & 47.3496 & 43.2912 & 50.3297 & 58.9391 & 75.9828 & - & 58.4618 \\
\hline 8. Japanese & 52.8261 & 67.0835 & 41.5611 & 99.8864 & 99.4177 & 111.4767 & 73.2348 & - \\
\hline
\end{tabular}

the Okhotsk culture series. In Figure 5, the Sakhalin Ainu sample, and to a lesser extent the northeastern Hokkaido Ainu sample, shift to the Okhotsk culture series.

The affinities between the samples presented in Figure 2 and Figure 4 are more or less different from each other. This may be at least in part attributed to additional information not included in the two-dimensional expression by MDS in
Figure 2 but included in Figure 4. The intergroup similarities shown in Figure 5 are parallel to those presented in Figure 3, because almost all variance was expressed in both Figure 3 and Figure 5. 
Table 7. Coordinate scores and contribution rates of multidimensional scaling based on Mahalanobis' generalized distances

\begin{tabular}{|c|c|c|c|c|c|c|c|c|c|c|c|c|c|}
\hline \multirow{3}{*}{ Sample names } & \multicolumn{4}{|c|}{ Males + Females } & \multicolumn{5}{|c|}{ Males } & \multicolumn{4}{|c|}{ Females } \\
\hline & \multicolumn{13}{|c|}{ Dimension } \\
\hline & 1 & 2 & 3 & 4 & 1 & 2 & 3 & 4 & 5 & 1 & 2 & 3 & 4 \\
\hline Southy & 4.879 & 4.611 & 10.301 & -4.281 & 14.311 & 7.174 & -2.876 & -19.550 & 15.493 & 20.517 & 4.159 & -10.839 & 21.361 \\
\hline out & 29.012 & -8.089 & & & & -6.219 & 8.508 & 2.370 & -1.829 & 1.400 & 9.917 & 17.265 & 3.919 \\
\hline Nort & & & 27.4 & -10.0 & 16.8 & 17.183 & -17.804 & -9.623 & -17.619 & -18.245 & -12.318 & 1.538 & -2.966 \\
\hline Sakhalin & 12.412 & 43.355 & 3.862 & 7.5 & 4.280 & 26.997 & 26.119 & 2.589 & 0.701 & -8.876 & 51.155 & -11.394 & 4.385 \\
\hline Jomon & 51.147 & -26.005 & -15.425 & 7.334 & 49.595 & -23.042 & -1.190 & 15.994 & 0.685 & 33.452 & 14.407 & 27.478 & -4.972 \\
\hline Epi-Jomo & -3.875 & -18.987 & -6.932 & -24.526 & -18.545 & -9.802 & -19.669 & -1.917 & 6.856 & 59.289 & -34.853 & -13.479 & 8.512 \\
\hline Okhotsk cu & -29.894 & 24.475 & -28.634 & -3.570 & -49.890 & 15.111 & -8.386 & 20.651 & 2.983 & 3.013 & 5.285 & -18.332 & -26.996 \\
\hline Modern J & -68.426 & -23.972 & 6.111 & 14.374 & -52.122 & -27.403 & 15.297 & -10.514 & -7.270 & -49.516 & -37.751 & 7.764 & -3.243 \\
\hline & 5.390 & & & & & & 10.928 & & & & 4.068 & 11.125 & \\
\hline umulative prop. (\%) & 55.390 & 80.532 & 92.667 & 100.000 & 60.292 & 77.066 & 87.994 & 95.908 & 100.000 & 46.904 & 80.972 & 92.097 & 100.00 \\
\hline
\end{tabular}

Table 8. Smith' MMD based on 11 nonmetric dental data

\begin{tabular}{|c|c|c|c|c|c|c|c|c|}
\hline & 1 & 2 & 3 & 4 & 5 & 6 & 7 & 8 \\
\hline 1. Southwest Hokkaido Ainu & - & & & & & & & \\
\hline 2. Southeast Hokkaido Ainu & 0.0034 & - & & & & & & \\
\hline 3. Northeast Hokkaido Ainu & 0.0871 & 0.0459 & - & & & & & \\
\hline 4. Sakhalin Ainu & 0.0097 & 0.0192 & 0.0648 & - & & & & \\
\hline 5. Jomon & 0.0676 & 0.0422 & 0.1416 & 0.0296 & - & & & \\
\hline 6. Epi-Jomon/Satsumon & 0.1302 & 0.1259 & 0.3472 & 0.2199 & 0.1862 & - & & \\
\hline 7. Okhotsk culture & 0.1352 & 0.1319 & 0.0189 & 0.0856 & 0.2192 & 0.4366 & - & \\
\hline 8. Japanese & 0.2016 & 0.1802 & 0.3963 & 0.1280 & 0.1207 & 0.1792 & 0.2664 & - \\
\hline
\end{tabular}

Table 9. Coordinate scores and contribution rates of multidimensional scaling based on MMDs

\begin{tabular}{lrr}
\hline \multirow{2}{*}{ Sample names } & \multicolumn{2}{c}{ Dimension } \\
\cline { 2 - 3 } & 1 & \multicolumn{1}{c}{2} \\
\hline Southwest Hokkaido Ainu & 0.004 & 0.064 \\
Southeast Hokkaido Ainu & 0.005 & 0.059 \\
Northeast Hokkaido Ainu & 0.224 & 0.113 \\
Sakhalin Ainu & 0.036 & -0.040 \\
Jomon & -0.041 & -0.008 \\
Epi-Jomon/Satsumon & -0.270 & 0.131 \\
Okhotsk culture & 0.233 & -0.119 \\
Modern Japanese & -0.191 & -0.200 \\
\hline Proportion (\%) & 69.903 & 30.097 \\
Cumulative prop. (\%) & 69.903 & 100.000 \\
\hline
\end{tabular}

\section{Discussion}

In spite of temporal and spatial differences, it is often emphasized that the present Ainu retain a number of phenotypic features that can be traced back to those of the Neolithic inhabitants of the Japanese archipelago, the Jomon lineage (Hanihara, 1991; Dodo and Kawakubo, 2002). However, recent genetic and morphological studies suggest interregional difference between local groups of the Jomon skeletal series, including the Hokkaido Jomon sample on the one hand (Adachi et al., 2009; Hanihara and Ishida, 2009), and a possible genetic influence from an external source on the early inhabitants of Hokkaido during the post-Jomon period on the other (Ishida, 1996; Shigematsu et al., 2004; Tajima et al., 2004; Sato et al., 2007, 2009; Hanihara et al., 2008; Hanihara, 2010a, b).
The present findings re-evaluate the relationships between the Jomon and recent Ainu based on metric and nonmetric dental traits. At the same time, however, as shown in Figure 2 and Figure 3, overall post-Neolithic spatial and temporal population continuity, from the Jomon to Ainu through the Epi-Jomon/Satsumon series, is not necessarily indicated in the case of female metric and sex-combined nonmetric analyses. Such discrepancies between sexes and types of data may confuse the interpretation of population affinities and history. In the present results, however, the discordance may be attributed at least in part to the sampling errors due to the relatively small sample sizes. This is particularly of concern regarding the female Epi-Jomon/Satsumon metric and combined-sex nonmetric datasets. At the same time, it remains possible that sex-related population history and subsistence pattern, as well as differential retention/speciation of phenotypic characteristics between metric and nonmetric dental features, have something to do with such discordance (Hanihara and Ishida, 2005; Hanihara et al., 2008; Hanihara, 2010a; Matsumura et al., 2009).

Using the $R$-matrix approach, one of the present authors (T.H.) indicated that among several local groups of the Ainu, the differentiation of cranial and dental features is distinct in the groups from the coastal region along the Sea of Okhotsk and the easternmost region of Hokkaido. Moreover, the northeastern Hokkaido Ainu group is more northern-like than the other Ainu series (Hanihara et al., 2008; Hanihara, $2010 a, b)$. Such patterns of differentiation were not necessarily detected in the results obtained in the present paper.

As presented in Figure 2, however, the Okhotsk culture sample clusters with the Hokkaido Ainu groups in females. Moreover, the female Okhotsk culture series shows closer 

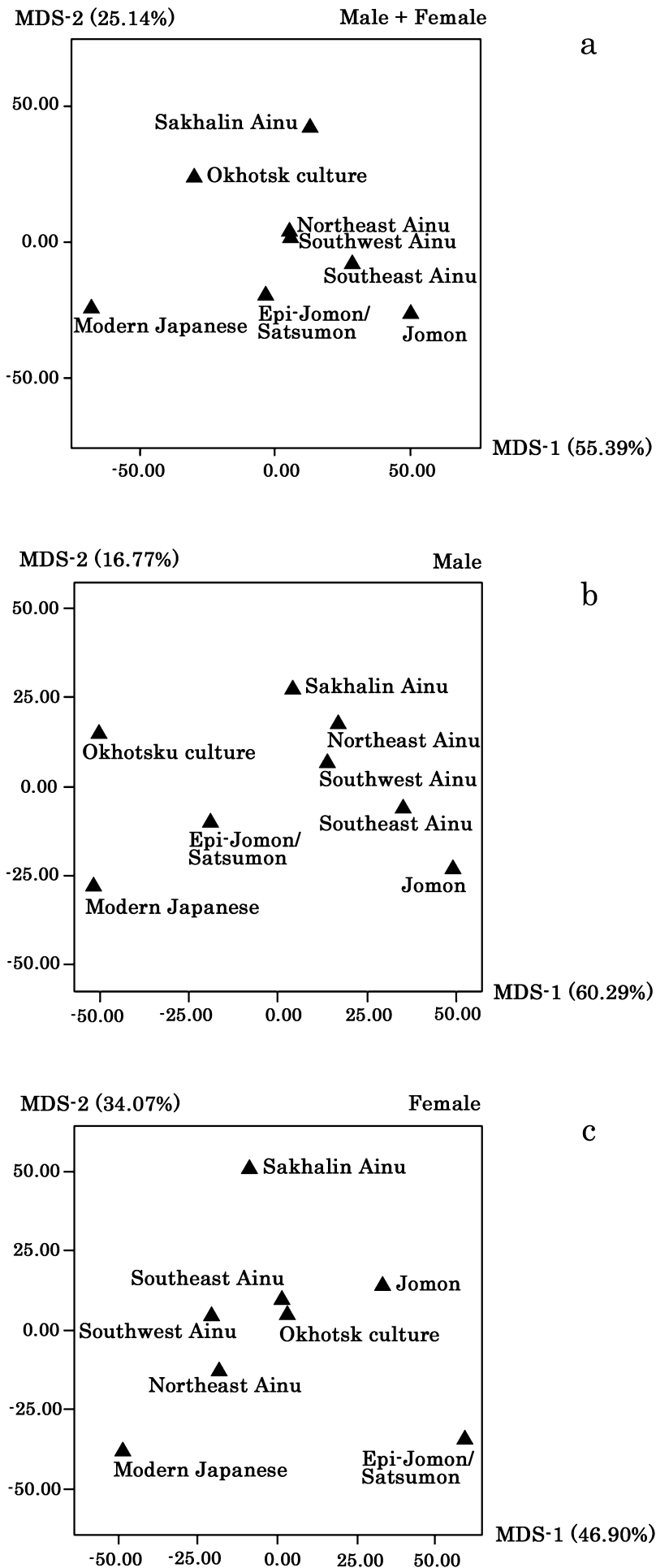

Figure 2. Two-dimensional scattergrams drawn by MDS based on Mahalanobis' generalized distance calculated by using odontometric data for sex-pooled (a), male (b), and female (c).

affinities to the northeastern Hokkaido Ainu than the male series in Figure 4 and Table 6. Similar results have been presented in previous craniometric studies (Hanihara et al., 2008). Furthermore, it has been pointed out that the affinities of the Ainu with Northeast Asians measured by mtDNA se-

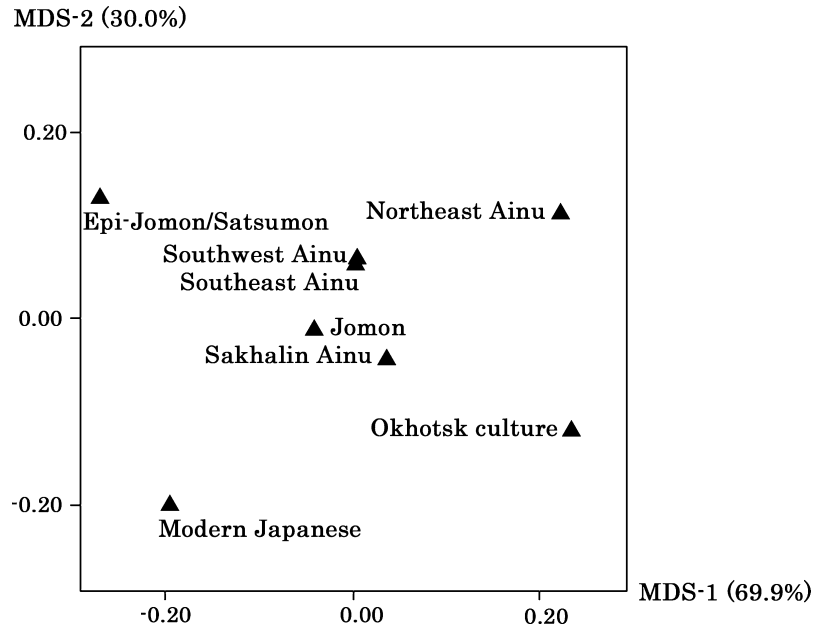

Figure 3. Two-dimensional expression drawn by using the MDS scores based on MMDs calculated from nonmetric dental data.

quence types (maternal lineage) are greater than those by Yhaplotypes (paternal lineage) (Tajima et al., 2004). Based on such findings, Tajima et al. (2004) suggested maternal contacts between the Ainu and Northeast Asians, or at least unidirectional migration from Northeast Asia to Hokkaido over time. Several researchers have suggested a higher female than male migration rate due to the widespread practice of patrilocality or a shorter matrilineal generation interval, at least on a global scale (Seielstad et al., 1998; Stoneking, 1998; Oota et al., 2001; Helgason et al., 2003; Wilder et al., 2004; Shriver, 2005). The different pattern of interpopulation relationships depending on sex presented herein reflect patrilocal residence or different generation time between males and females, although larger skeletal samples are needed to confirm this hypothesis.

The Sakhalin Ainu series show again more or less close affinities to the Okhotsk culture series as suggested in the previous studies (Ishida and Kida, 1991; Ishida, 1996; Hanihara et al., 2008; Matsumura et al., 2009). However, archeological evidence suggests that the Ainu expanded from Hokkaido to the Sakhalin Island during the 14th and 15th centuries AD (Ohyi, 1985; Ishida and Kida, 1991; Hanihara, 1998; Fitzhugh and Dubreuil, 1999), long after the Okhotsk culture had disappeared from both Hokkaido and Sakhalin. The northern part of the Sakhalin island group has been inhabited by other ethnic groups: Nivkh, Uilta, and Orochs (Ishida and Kida, 1991; Matsumura et al., 2009). Taking these into account, the northern-like characteristics of the Sakhalin Ainu may be explained by a genetic contribution of more recent indigenous groups of Sakhalin Island.

Classic analysis of biological distances between populations such as Mahalanobis' generalized distance for metric data and Smith's MMD distance for nonmetric data has been a central method in studies of the reconstruction of population history (Relethford and Blangero, 1990; Relethford, 1994). However, a potential danger in these studies is that such methods will only be useful when factors such as gene flow, genetic drift, climatic and subsistence adaptation, etc., which have had an impact on morphological variation that 

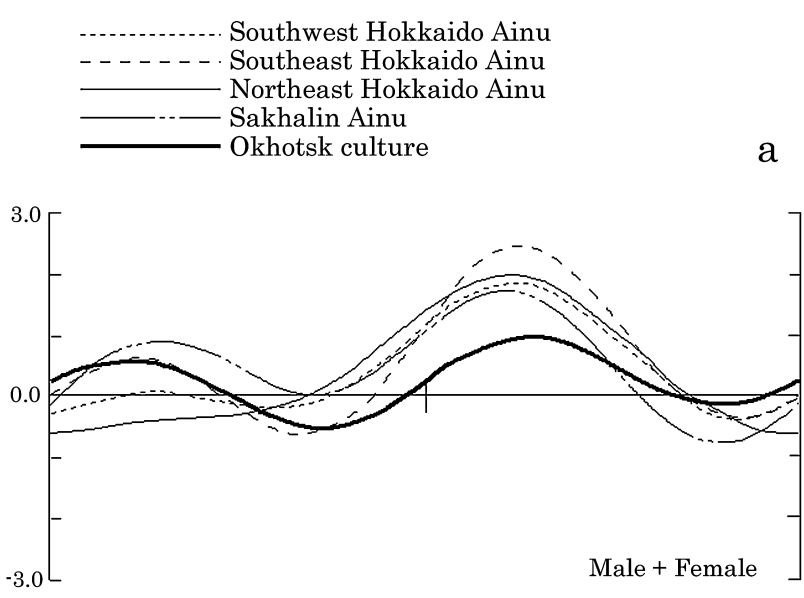

$\mathrm{b}$

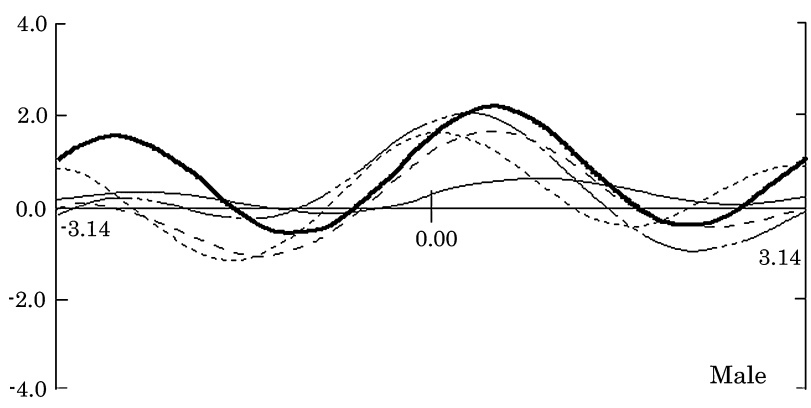

C

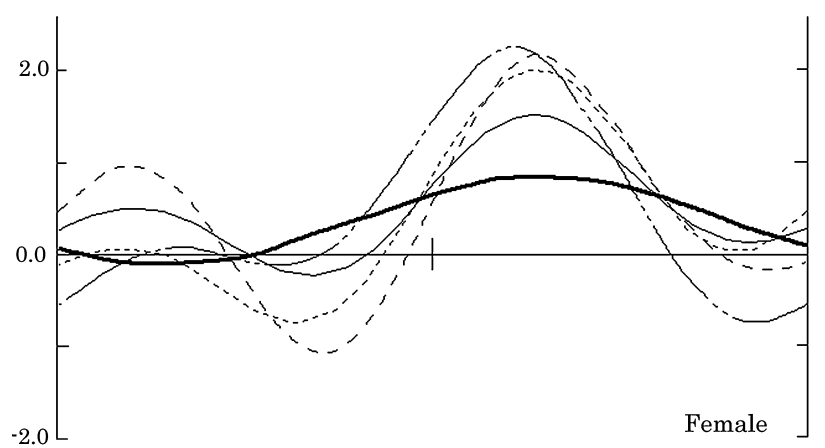

Figure 4. A multidimensional plots (Andrews, 1972) for the four local Ainu samples and the Okhotsk culture series based on the MDS scores calculated from odontometric data: (a) sex-combined samples; (b) male samples; (c) female samples.

reflect affinities between populations, have an effect large enough to be detected. If the effects of such factors are small, comparative morhopological analysis may not detect them. The present findings do imply a substantial interpopulation relationship between the Okhotsk culture people and Ainu-Jomon lineages at least in northeastern Hokkaido, along the coastal region of the Sea of the Okhotsk, as pointed out in previous studies (Shigematsu et al., 2004; Hanihara et al., 2008; Hanihara, 2010a, b). This suggests that gene flow to northeastern Hokkaido from an external source after the Jomon periods cannot be disregarded.

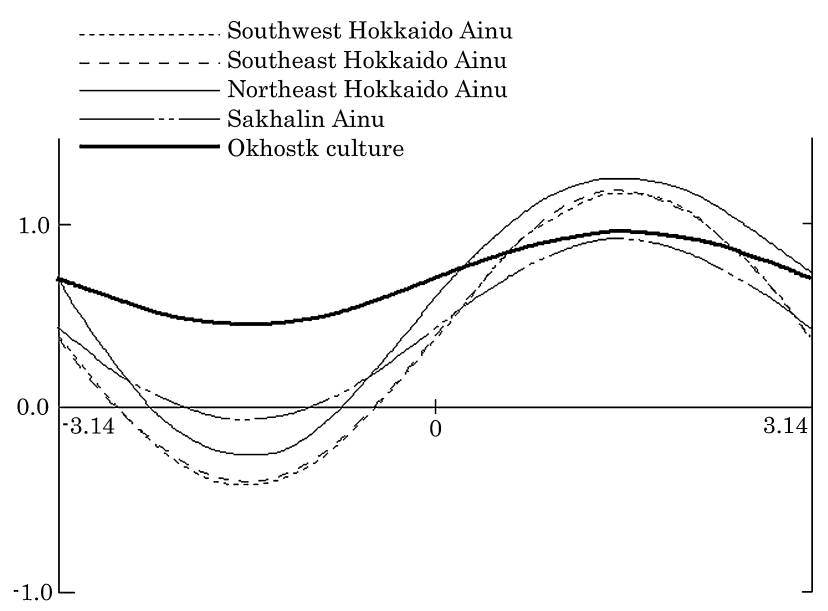

Figure 5. A multidimensional plot (Andrews, 1972) for the four local Ainu samples and the Okhotsk culture series based on the MDS scores calculated from nonmetric dental data.

\section{Acknowledgments}

We thank Gen Suwa, the associate editor, for his constructive suggestions for improving the manuscript. We wish to express our sincere thanks to T. Amano of Hokkaido University Museum, Sapporo; M. Matsumura of the Department of Anatomy, Sapporo Medical University, Sapporo; Y. Dodo of the Department of Anatomy, Tohoku University School of Medicine, Sendai; G. Suwa of the Department of Anthropology, University Museum, The University of Tokyo, Tokyo; H. Baba of the Department of Anthropology, National Museum of Nature and Science, Tokyo; K. Katayama of the Department of Zoology, Kyoto University, Kyoto; for their kind permission to study the materials under their care. This study was supported in part by Grants-in-Aid for Scientific Research (Nos. 18570220 and 21405027 to T.H.) from the Ministry of Education, Culture, Sports, Science and Technology of Japan; a Japan Fellowship for Research in United Kingdom (T.H.) from the Japan Society for the Promotion of Science; and the Smithsonian Institution Fellowship Program, Smithsonian Opportunities for Research and Study (Senior Fellowship in 2001-2002 to T.H.).

\section{References}

Adachi N., Shinoda K., Umetsu K., and Matsumura H. (2009) Mitochondrial DNA analysis of Jomon skeletons from the Funadomari site, Hokkaido, and its implication for the origins of Native American. American Journal of Physical Anthropology, 138: 255-265.

Amano T. (2003) What is the Okhotsk culture? In: Nomura T. and Utagawa Y. (eds.), Epi-Jomon and Okhotsk culture. Hokkaido Sinbun-sha, Sapporo, pp. 110-133 (in Japanese).

Andrews D.F. (1972) Plots of high-dimensional data. Biometrics, 28: $125-136$.

Berry A.C. and Berry R.J. (1967) Epigenetic variation in the human cranium. Journal of Anatomy, 101: 361-379.

Brace C.L. and Hunt K.D. (1990) A nonracial craniofacial perspective on human variation A(ustralia) to Z(uni). American Journal of Physical Anthropology, 82: 341-360.

Brace C.L., Brace M.L., and Leonard W.L. (1989) Reflections on the face of Japan: a multivariate craniofacial and odontometric 
perspective. American Journal of Physical Anthropology, 78: 93-113.

Brace C.L., Rosenberg K.R., and Hunt K.D. (1991) What big teeth you had grandma! Human tooth size, past and present. In: Kelly M.A. and Larsen C.S. (eds.), Advances in Dental Anthropology. Wiley-Liss, New York, pp. 33-57.

Brace C.L., Nelson A.R., Seguchi N., Oe H., Sering L., Pan Q., Li Y., and Tumen D. (2001) Old World sources of the first New World human inhabitants: a comparative craniofacial view. Proceedings of National Academy of Science USA, 98: 10017-10022.

Constandse-Westermann T.S. (1972) Coefficients of Biological Distance. Humanities Press, New York.

Dahlberg A.A. (1949) The dentition of the America Indian. In: Laughlin W.S. (ed.), The Physical Anthropology of the American Indian. The Viking Fund, New York, pp. 138-174.

Dahlberg A.A. (1963) Analysis of the American Indian dentition. In: Brothwell D.R. (ed.), Dental Anthropology. Pergamon Press, Oxford, pp. 149-177.

Dodo Y. and Ishida H. (1990) Population history of Japan as viewed from cranial nonmetric variation. Journal of the Anthropological Society of Nippon, 98: 269-287.

Dodo Y. and Kawakubo Y. (2002) Cranial affinities of the EpiJomon inhabitants in Hokkaido, Japan. Anthropological Science, 110: 1-32.

Fitzhugh W.W. and Dubreuil C.O. (1999) Ainu: Spirit of a Northern People. National Museum of Natural History, Washington $\mathrm{DC}$

Habu J. (2004) Ancient Jomon of Japan. Cambridge University Press, Cambridge.

Hanihara K. (1968) Mongoloid dental complex in the permanent dentition. Proceedings VIIIth International Congress of Anthropological and Ethnological Sciences, 1: 298-300.

Hanihara K. (1970) Mongoloid dental complex in the deciduous dentition, with special reference to the dentition of the Ainu. Journal of the Anthropological Society of Nippon, 78: 3-17.

Hanihara K. (1991) Dual structure model for the population history of the Japanese. Japan Review, 2: 1-33.

Hanihara K. (1998) Reanalysis of local variations in the Ainu crania. Anthropological Science, 106 (supplement): 1-15.

Hanihara K., Tanaka T., and Tamada M. (1970) Quantitative analysis of the shovel shaped character in the incisors. Journal of the Anthropological Society of Nippon, 78: 90-98.

Hanihara T. (1992) Negritos, Australian Aborigines, and 'protosundadont' dental pattern. American Journal of Physical Anthropology, 88: 183-196.

Hanihara T. (1997) Craniofacial affinities of Mariana Islanders and circum-Pacific peoples. American Journal of Physical Anthropology, 104: 411-425.

Hanihara T. (2008) Morphological variation of major human populations based on nonmetric dental traits. American Journal of Physical Anthropology, 136: 169-182.

Hanihara T. (2010a) Metric and nonmetric dental variation and population structure of the Ainu. American Journal of Human Biology, 22: 163-171

Hanihara T. (2010b) Nonmetric cranial variation and diversification of the Ainu. In: Columbus F. (ed.), Phylogeography: Concepts, Intraspecific Patterns and Speciation Processes. Nova Science Publisher, New York (in press).

Hanihara T. and Ishida H. (2005) Metric dental variation of major human population in the world. American Journal of Physical Anthropology, 128: 287-298.

Hanihara T. and Ishida H. (2009) Regional differences in craniofacial diversity and the population history of Jomon Japan. American Journal of Physical Anthropology, 139: 311-322.

Hanihara T., Ishida H., and Dodo Y. (2003) Characterization of biological diversity through analysis of discrete cranial traits. American Journal of Physical Anthropology, 121: 241-251.

Hanihara T., Yoshida K., and Ishida H. (2008) Craniometric variation of the Ainu: an assessment of differential gene flow from
Northeast Asia into northern Japan, Hokkaido. American Journal of Physical Anthropology, 137: 283-293.

Helgason A., Hrafnkelsson B., Gulcher J.R., Ward R., and Stefánnson K. (2003) A populationwide coalescent analysis of Icelandic matrilineal and patrilineal genealogies: evidence for a faster evolutionary rate of mtDNA lineages than Y chromosomes. American Journal of Human Genetics, 72: 1370 1388.

Horai S., Kondo R., Murayama K., Hayashi S., Koike H., and Nakai N. (1991) Phylogenetic affiliation of ancient and contemporary humans inferred from mitochondrial DNA. Philosophical Transactions of the Royal Society B Biological Science, 333: 409-417.

Howells W.W. (1986) Physical anthropology of the prehistoric Japanese. In: Pearson R.J. (ed.), Windows on Japanese Past: Studies in Archaeology and Prehistory. Center for Japanese Studies, The University of Michigan, Ann Arbor, pp. 85-99.

Howells W.W. (1989) Skull shapes and the map: craniometric analyses in the dispersion of modern Homo. Papers of the Peabody Museum of Archaeology and Ethnology 79. Harvard University, Cambridge.

Irish J.D. (1997) Characteristic high- and low-frequency dental traits in Sub-Saharan African populations. American Journal of Physical Anthropology, 102: 455-467.

Irish J.D. (1998) Ancestral dental traits in recent Sub-Saharan Africans and the origins of modern humans. Journal of Human Evolution, 34: 81-98.

Ishida H. (1988) Morphological studies of Okhotsk crania from Omisaki, Hokkaido. Journal of the Anthropological Society of Nippon, 96: 17-45.

Ishida H. (1996) Metric and nonmetric cranial variation of the prehistoric Okhotsk people. Anthropological Science, 104: 233 258.

Ishida H. and Kida M. (1991) An anthropological investigation of the Sakhalin Ainu with special reference to nonmetric cranial traits. Journal of the Anthropological Society of Nippon, 99: 23-32.

Jungers W.L., Falsetti A.B., and Wall C.E. (1995) Shape, relative size, and size-adjustments in morphometrics. Yearbook of Physical Anthropology, 38: 137-161.

Kawakubo Y., Hanihara T., Shigematsu M., and Dodo Y. (2009) Interpretation of craniometric variation in northeastern Japan, the Tohoku region. Anthropological Science, 117: 57-65.

Komesu A., Hanihara T., Amano T., Ono H., Yoneda M., Dodo Y., Fukumine T., and Ishida H. (2008) Nonmetric cranial variation in human skeletal remains associated with Okhotsk culture. Anthropological Science, 116: 33-47.

Kondo O. (1995) An analysis of Ainu population structure, based on cranial morphology. Anthropological Science, 103: 369384.

Kozintsev A. (1990) Ainu, Japanese, their ancestors and neighbours: cranioscopic data. Journal of the Anthropological Society of Nippon, 98: 247-267.

Kozintsev A. (1992) Prehistoric and recent populations of Japan: multivariate analysis of cranioscopic data. Arctic Anthropology, 29: 104-111.

Mahalanobis P.C. (1936) On the generalized distance in statistics. Proceedings of the National Institute of Sciences of India, 2: 49-55.

Manabe Y., Kitagawa Y., Oyamada J., Igawa K., Kato K., Kikuchi N., Maruo H., Kobayashi S., and Rokutanda A. (2008) Population history of the northern and central Nansei islands (Ryukyu island arc) based on dental morphological variations: gene flow from North Kyushu to Nansei Islands. Anthropological Science, 116: 49-65.

Matsumura H. (1995) Dental characteristics affinities of the prehistoric to the modern Japanese with the East Asians, American natives and Australo-Melanesians. Anthropological Science, 103: 235-261.

Matsumura H. (2007) Non-metric dental trait variation among 
local sites and regional groups of the Neolithic Jomon period, Japan. Anthropological Science, 115: 25-33.

Matsumura H. and Hudson M.J. (2005) Dental perspectives on the population history of Southeast Asia. American Journal of Physical Anthropology, 127: 182-209.

Matsumura H., Ishida H., Amano T., Ono H., and Yoneda M. (2009) Biological affinities of Okhotsk culture people with East Siberians and Arctic people based on dental characteristics. Anthropological Science, 117: 121-132.

Mayhall J.T., Saunders S.R., and Belier P.L. (1982) The dental morphology of North American whites: a reappraisal. In: Kurten B. (ed.), Teeth: Form, Function, and Evolution. Columbia University Press, New York, pp. 245-258.

Nei M. (1995) The origins of human populations: genetic, linguistic, and archeological data. In: Brenner S. and Hanihara K. (eds.), The Origin and Past of Modern Human as Viewed from DNA. World Scientific, Singapore, pp. 71-91.

Ohyi H. (1985) On the process of crystallization of Sakhalin Ainu. Bulletin of the Institute for the Study of North Eurasian Culture, Hokkaido University, 17: 165-192.

Omoto K. (1972) Polymorphisms and genetic affinities of the Ainu in Hokkaido. Human Biology in Oceania, 1: 279-288.

Omoto K. (1995) Genetic diversity and the origins of the 'Mongoloids.' In: Brenner S. and Hanihara K. (eds.), The Origin and Past of Modern Human as Viewed from DNA. World Scientific, Singapore, pp. 92-109.

Omoto K. and Saitou N. (1997) Genetic origins of the Japanese: a partial support for the dual structure hypothesis. American Journal of Physical Anthropology, 102: 437-446.

Oota H., Settheetham-Ishida W., Tiwawech D., Ishida T., and Stoneking M. (2001) Human mtDNA and Y-chromosome variation is correlated with matrilocal versus patrilocal residence. Nature Genetics, 29: 20-21.

Ossenberg N.S., Dodo Y., Maeda T., and Kawakubo Y. (2006) Ethnogenesis and craniofacial change in Japan from the perspective of nonmetric traits. Anthropological Science, 114: 99-115.

Pietrusewsky M. (1997) The people of Ban Chiang: an early bronze-age site in northeast Thailand. Bulletin of the IndoPacific Prehistory Association, 16: 119-148.

Relethford J.H. (1994) Craniometric variation among modern human populations. American Journal of Physical Anthropology, 95: 53-62.

Relethford J.H. (2009) Race and global patterns of phenotypic variation. American Journal of Physical Anthropology, 139: $16-22$.

Relethford J.H. and Blangero J. (1990) Detection of differential gene flow from patterns of quantitative variation. Human Biology, 62: 5-25.

Sato T., Amano T., Ono H., Ishida H., Kodera H., Matsumura H., Yoneda M., and Masuda R. (2007) Origins and genetic features of the Okhotsk people, revealed by ancient mitochondrial DNA analysis. Journal of Human Genetics, 52: 18-627.

Sato T., Amano T, Ono H., Ishida $\mathrm{H}$., Kodera $\mathrm{H}$, Matsumura $\mathrm{H}$, Yoneda M., and Masuda R. (2009) Mitochondrial DNA haplogrouping of the Okhotsk people based on analysis of ancient DNA: an intermediate of gene flow from the continental Sakhalin people to the Ainu. Anthropological Science, 117: $171-180$.

Scott G.R. and Turner C.G. II (1997) The Anthropology of Mod- ern Human Teeth: Dental Morphology and its Variation in Recent Human Populations. Cambridge University Press, Cambridge.

Seielstad M.T., Minch E., and Cavalli-Sforza L.L. (1998) Genetic evidence for a higher female migration rate in humans. Nature Genetics, 20: 278-280.

Shigematsu M., Ishida H., Goto M., and Hanihara T. (2004) Morphological affinities between Jomon and Ainu: reassessment based on nonmetric cranial traits. Anthropological Science, 112: $161-172$

Shriver M.D. (2005) Female migration rate might not be greater than male rate. European Journal of Human Genetics, 13: $131-132$.

Stoneking M. (1998) Women on the move. Nature Genetics, 20: 219-220.

Tajima A., Hayami M., Tokunaga K., Juji T., Matsuo M., Marzuki S., Omoto K., and Horai S. (2004) Genetic origins of the Ainu inferred from combined DNA analyses of maternal and paternal lineages. Journal of Human Genetics, 49: 187-193.

Torgerson W.S. (1952) Multidimensional scaling I: theory and method. Psychometrika, 17: 401-419.

Turner C.G., II (1987) Late Pleistocene and Holocene population history of East Asia based on dental variation. American Journal of Physical Anthropology, 73: 305-321.

Turner C.G., II (1990) Major features of sundadonty and sinodonty, including suggestions about East Asian microevolution, population history, and late Pleistocene relationships with Australian Aboriginals. American Journal of Physical Anthropology, 82: 295-317.

Turner C.G., II (1992a) Sundadonty and sinodonty in Japan: the dental basis for a dual origin hypothesis for the peopling of the Japanese islands. In: Hanihara K. (ed.), Japanese as a Member of the Asian and Pacific Populations. International Research Center of Japanese Studies, Kyoto, pp. 96-112.

Turner C.G., II (1992b) Microevolution of East Asian and European populations: a dental perspective. In: Akazawa T., Aoki K., and Kimura T. (eds.), The Evolution and Dispersal of Modern Humans in Asia. Hokusensha, Tokyo, pp. 415-438.

Turner C.G., II, Nichol C.R., and Scott G.R. (1991) Scoring procedures for key morphological traits of the permanent dentition: The Arizona State University dental anthropology system. In: Kelley M.A. and Larsen C.S. (eds.), Advances in Dental Anthropology. Wiley-Liss, New York, pp. 13-31.

Weidenreich F. (1937) The Dentition of Sinanthropus pekinensis: A Comparative Odontography of the Hominids. Paleontologica Sinica NSD No. 1, Beijing.

Wilder J.A., Kingan S.B., Mobasher Z., Pilkington M.M., and Hammer M.F. (2004) Global patterns of human mitochondrial DNA and Y-chromosome structure are not influenced by higher migration rates of females versus males. Nature Genetics, 36: 1122-1125.

Yamaguchi B. (1967) A comparative osteological study of the Ainu and Australian Aborigines. Human Biology Series No. 2. Australian Institute of Aboriginal Studies, Canberra.

Yamaguchi B. (1973) Facial flatness measurements of the Ainu and Japanese crania. Bulletin of the National Science Museum, Tokyo, D16: 161-171.

Yamaguchi B. (1982) A review of the osteological characteristics of the Jomon population in prehistoric Japan. Journal of the Anthropological Society of Nippon, 90 (supplement): 77-90. 